\title{
Relationship of glucose intolerance to coronary risk in Afro-Caribbeans compared with Europeans
}

\author{
N. Chaturvedi ${ }^{1}$, P.M. McKeigue ${ }^{2}$, M. G. Marmot ${ }^{1,2}$ \\ ${ }^{1}$ Department of Epidemiology and Public Health, University College and Middlesex School of Medicine, London, UK \\ ${ }^{2}$ Department of Epidemiology and Population Sciences, London School of Hygiene and Tropical Medicine, London, UK
}

Summary Afro-Caribbeans have low mortality rates from coronary heart disease, despite a high prevalence of diabetes mellitus. We examined 1166 Afro-Caribbean and European men and women aged 40-64 years in a community survey in London, UK. Prevalence of glucose intolerance (combining impaired glucose tolerance, new and known diabetes) was $31 \%$ in AfroCaribbeans and $14 \%$ in Europeans $(p<0.001)$. In men, the prevalence of probable coronary heart disease was $6 \%$ in Afro-Caribbeans and $13 \%$ in Europeans $(p<0.01)$. Triglyceride was lower in Afro-Caribbeans than Europeans; in men, HDL cholesterol was higher. Afro-Caribbean men were less centrally obese, while Afro-Caribbean women were more centrally obese than their European counterparts. Fasting and 2-h insulin levels were higher in Afro-Caribbeans than Europeans. Glucose intolerance was associated with high triglyceride, low HDL cholesterol and central obesity in European but not in Afro-Caribbean men.
In Europeans, fasting triglyceride was $1.49 \mathrm{mmol} / \mathrm{l}$ in normoglycaemic and $1.89 \mathrm{mmol} / \mathrm{l}$ in glucose intolerant men $(p<0.05)$, in Afro-Caribbean men triglyceride was 1.08 and $1.22 \mathrm{mmol} / \mathrm{l}$, respectively. Waist hip ratio was 0.94 in normoglycaemic, and 0.98 in glucose intolerant European men $(p<0.001)$. In Afro-Caribbean men, waist hip ratio was 0.93 in both groups. At each level of insulin, glucose or central obesity, triglyceride was lower in Afro-Caribbean men and women than in Europeans. We speculate that despite high insulin levels, Afro-Caribbeans have a favourable lipoprotein pattern which persists in the presence of glucose intolerance, and may be related to body fat distribution. This could begin to explain their low rates of coronary heart disease. [Diabetologia (1994) 37: 765-772]

Key words Lipoproteins, obesity, insulin resistance, skinfolds.
Insulin resistance is thought to be the key to the close association observed between CHD and NIDDM [1]. But the mortality experience of Caribbean born migrants to the United Kingdom provides a striking contrast to this observed association. While mortality asso-

Received: 25 November 1993

and in revised form: 10 March 1994

Corresponding author: Dr. N. Chaturvedi, Department of Epidemiology and Public Health, University College and Middlesex School of Medicine, 66-72 Gower Street, London WC1 E 6EA, UK

Abbreviations: CHD, Coronary heart disease; WHR, waist hip ratio; WTR, waist thigh ratio; BMI, body mass index; NIDDM, non-insulin-dependent diabetes mellitus ciated with diabetes is between three and four times, (in men and women, respectively) that of the general population; mortality from CHD in Caribbean born men is half that, and in women is three quarters that of the general population [2]. This mortality paradox has been noted in other countries with migrant black populations such as the USA and the Caribbean. African American and Afro-Caribbean people have a high prevalence of diabetes and high mortality rates associated with diabetes [3-5] and yet relatively low mortality rates from $\mathrm{CHD}$ [4-6].

This apparent protection from CHD may be related to the favourable lipoprotein pattern of low triglyceride and high HDL cholesterol in black populations observed in the United States, the United Kingdom and the Caribbean $[5,7,8]$. If these ethnic differences in 
Table 1. Age standardised prevalence of glucose intolerance and diabetes by sex and ethnicity (number in brackets)

\begin{tabular}{|c|c|c|c|c|}
\hline \multirow{2}{*}{$\begin{array}{l}\text { Glucose } \\
\text { intolerance } \\
\text { category }\end{array}$} & \multicolumn{2}{|l|}{ Men } & \multicolumn{2}{|l|}{ Women } \\
\hline & $\begin{array}{l}\text { European } \\
n=272\end{array}$ & $\begin{array}{l}\text { Afro-Caribbean } \\
n=245\end{array}$ & $\begin{array}{l}\text { European } \\
n=310\end{array}$ & $\begin{array}{l}\text { Afro-Caribean } \\
n=330\end{array}$ \\
\hline Impaired glucose tolerance & $9.1 \%(25)^{\mathrm{a}}$ & $14.7 \%(37)$ & $9.0 \%(28)^{\mathrm{c}}$ & $16.1 \%(53)$ \\
\hline Undiagnosed diabetes & $3.2 \%(9)$ & $4.1 \%(11)$ & $2.1 \%(6)^{c}$ & $6.7 \%(22)$ \\
\hline Known diabetes & $3.3 \%(9)^{\mathrm{b}}$ & $8.8 \%(21)$ & $1.9 \%(6)^{c}$ & $11 \%(36)$ \\
\hline
\end{tabular}

${ }^{\mathrm{a}} p<0.05 ;{ }^{\mathrm{b}} p<0.01 ;{ }^{\mathrm{c}} p<0.001$; for the ethnic difference by sex

lipoprotein patterns are also present in people with diabetes [9], and in people with impaired glucose tolerance, this would provide an indication as to why the high rate of diabetes in black populations is not accompanied by a high rate of CHD.

We determined the prevalence of diabetes and coronary heart disease, and compared lipoprotein and obesity patterns in Afro-Caribbeans and Europeans in the United Kingdom in normoglycaemic and glucose intolerant subjects.

\section{Subjects and methods}

Methods have been described in detail elsewhere [10]. We examined 1166 Afro-Caribbean and European men and women aged 40-64 years drawn from six family doctor practices in the inner London borough of Brent. Subjects, matched by ethnicity, 5-year age group and sex, were selected at random from family doctor lists and invited to participate in the study.

Subjects were sent a questionnaire to complete before their appointment and asked to attend at a local health centre after an overnight fast. The questionnaire included items on: previous medical history, current medication, the Rose angina questionnaire and health-related behaviour. The questionnaire was checked and completed at the health centre and ethnicity assigned on the basis of appearance and parental origin. The following tests were then performed: 12-lead ECG, height, weight and body fat measurements. The body fat measurements included body circumferences and skinfold thicknesses measured by four trained observers. One observer acted as the standard and periodic standardisation measurements were made during the study to ensure good inter-observer reliability. Circumferences round the mid arm, waist (least between the costal margin and iliac crest), hip (over the greater trochanter), maximum thigh (with foot resting on a chair) were measured using a fibreglass tape with a spring balance to hold the tape at a constant tension of $600 \mathrm{~g}$. Sagittal diameter was measured at the level of the iliac crests in the supine position with a Harpenden anthropometer (CMS Weighing Instruments, London, UK). Holtain calipers were used to measure the following subcutaneous skinfold thicknesses: triceps, subscapular, supra-iliac, and anterior thigh. All skinfolds were measured on the right hand side where possible. Coefficients of variation for body size were: height $5 \%$, weight $18 \%$, circumferences; sagittal $17 \%$, waist $14 \%$, thigh $10 \%$, hip $9 \%$, skinfolds; triceps $52 \%$, subscapular $51 \%$, suprailiac $46 \%$, and anterior thigh $60 \%$.

Fasting and 2-h blood samples were taken after a 75-g glucose load in those who were not already known to have diabetes. Glucose was determined by the hexokinase method (Roche, Basel, Switzerland) and insulin levels were analysed by the Elisa technique (Boehringer Mannheim, Mannheim, Germany) [11]. Cholesterol was measured by the cholesterol oxidase-peroxi- dase colorimetric method (Boehringer Mannheim, Mannheim, Germany) [12]. Cholesterol in the HDL fraction was determined after magnesium chloride-dextran sulphate precipitation (Technicon, Tournai, Belgium) [13]. Triglycerides were measured by the glycerol 3-phosphate oxidase peroxidase colorimetric method (Wako, Osaka, Japan). Apolipoprotein B was determined by the immunoturbidometric method [14]. Coefficients of variation for laboratory tests were: glucose $3.2 \%$, insulin $3.6 \%$, cholesterol $1.6 \%$, HDL cholesterol $2.3 \%$, triglyceride $2.6 \%$, and apolipoprotein B $2.7 \%$. Proinsulin cross-reactivity for this assay is $40 \%$.

Diabetes was defined according to World Health Organisation criteria, based on the results of the one glucose tolerance test [15]. Subjects with impaired glucose tolerance are at high risk of developing diabetes and associated cardiovascular disease. Therefore, those with impaired glucose tolerance and newly-diagnosed diabetes were combined as "glucose intolerant" and risk factors for CHD were compared with those with normoglycaemia. Nine subjects could not be assigned to a glucose tolerance category due to incomplete data.

All ECGs were Minnesota coded [16] by two experienced coders, coding disagreements were resolved by the senior coder. In men, "probable CHD", was defined as either major $Q$ waves on ECG (1-1 and 1-2), a doctor's previous diagnosis of CHD, or a positive response to the Rose angina questionnaire. Estimation of the prevalence of CHD in women is limited by the poor validity of the Rose angina questionnaire in women [17], and our numbers were too small to compare ECG abnormalities associated with CHD.

\section{Statistical analysis}

Age adjusted means are calculated as the values predicted by the regression model when age variables are held at their mean value. Prevalence rates are expressed after directly standardising to the combined age distribution of the study population. Insulin, cholesterol, HDL cholesterol, triglyceride and BMI were $\log$ transformed before analysis.

\section{Results}

Prevalence of coronary heart disease and glucose intolerance: European men had twice the age-standardised prevalence of probable CHD compared with Afro-Caribbeanmen $(13 \%$ (95\% C.I. $9-17 \%)$ vs $6 \%$ (95\% C.I. $3-9 \%), p<0.01)$. Prevalence rates were recalculated for those with glucose intolerance (i.e. impaired glucose tolerance, undiagnosed or known diabetes); in men, the prevalence of probable CHD was $17 \%$ in Europeans compared with $6 \%$ in Afro-Caribbeans $(p=0.03)$. 
Table 2. Age adjusted means of metabolic data by sex and ethnicity comparing normoglycaemic and glucose intolerant subjects

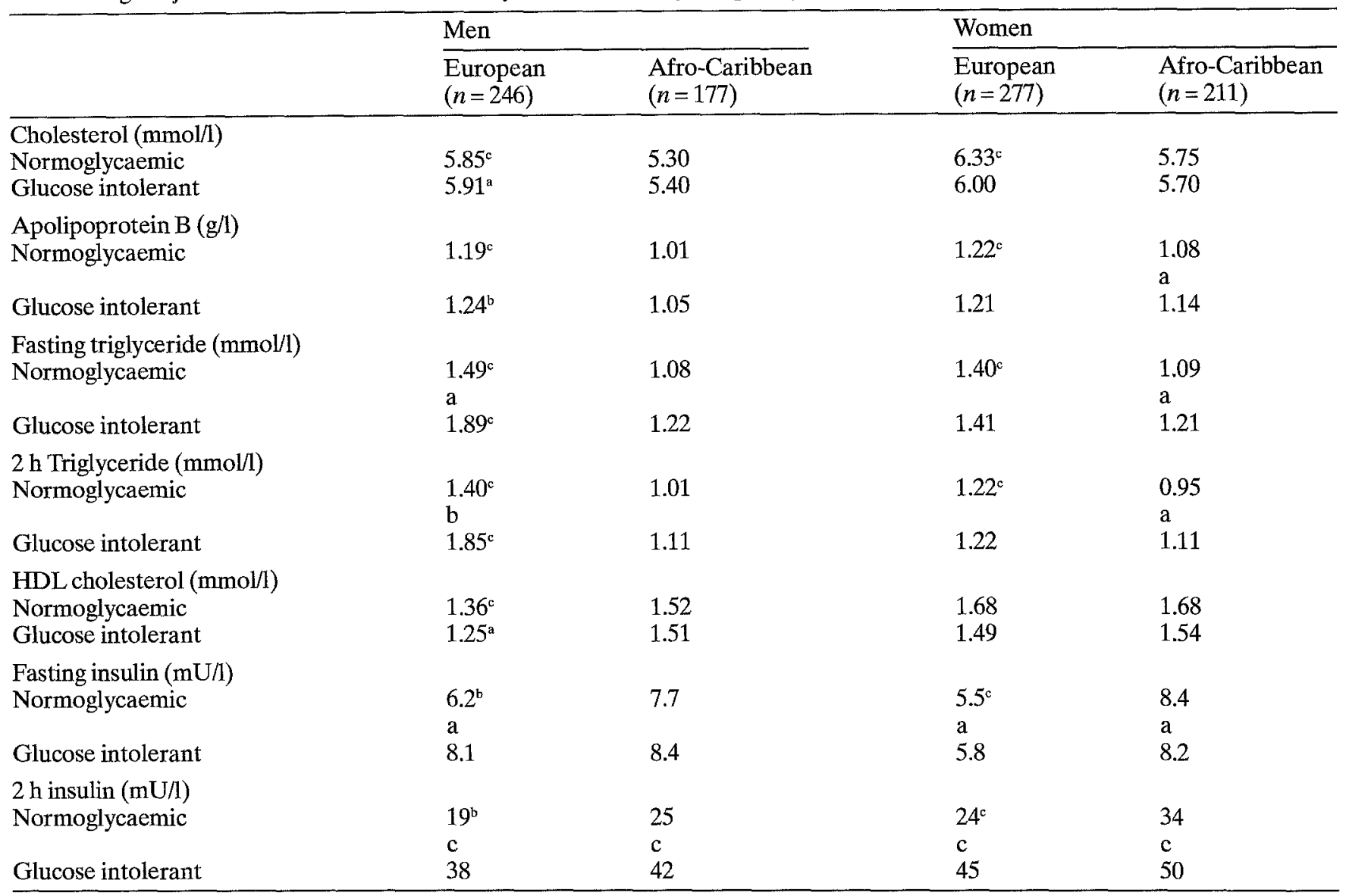

${ }^{\mathrm{a}} p<0.05 ;{ }^{\mathrm{b}} p<0.01 ;{ }^{\mathrm{c}} p<0.001$ (excludes subjects with known diabetes or hypertension)

The age-standardised prevalence of glucose intolerance (Table 1) was 1.8 times greater in Afro-Caribbean men compared with European men, and 2.6 times greater in Afro-Caribbean women compared with European women.

Lipids and apolipoprotein $B$ by glucose tolerance in Europeans and Afro-Caribbeans. Individuals with known diabetes or those on medication for hypertension were excluded from the analyses in Tables 2-4. These present data for the 139 glucose intolerant (impaired glucose tolerance and undiagnosed diabetes) subjects compared with normoglycaemic subjects. For both normoglycaemic and glucose intolerant subjects, total cholesterol, fasting and $2-\mathrm{h}$ triglyceride and apolipoprotein B were significantly lower, and HDL cholesterol was significantly higher in Afro-Caribbean men compared with European men. In European men, fasting and 2-h triglyceride levels were significantly higher in glucose intolerant subjects compared with normoglycaemic subjects, and HDL cholesterol was lower. In Afro-Caribbean men, there were no significant differences in these lipoprotein variables when normoglycaemic and glucose intolerant subjects were compared.
In normoglycaemic women, total cholesterol, fasting and 2-h triglyceride levels, and apolipoprotein B were lower in Afro-Caribbeans than in Europeans, but there was no difference in HDL cholesterol. When glucose intolerant subjects were compared, there were no significant differences in lipoprotein patterns between Europeans and Afro-Caribbeans. While triglyceride and apolipoprotein B levels were significantly higher in Afro-Caribbean women with glucose intolerance compared with normoglycaemic subjects, there was very little change in these indices for European women.

Adjusting for smoking, alcohol intake and exercise did not alter these ethnic differences in lipoproteins.

Relationship between insulin, glucose and lipoproteins. Both fasting and 2-h insulin levels were significantly higher in Afro-Caribbeans than in Europeans in normoglycaemic subjects, and higher, but not significantly, in glucose intolerant subjects (Table 2).

Triglyceride levels were positively correlated with insulin and glucose, and negatively correlated with HDL cholesterol in all four sex/ethnic groups. The strongest correlations were between fasting glucose and fasting triglyceride, and 2-h insulin and 2-h trigly- 
Table 3. Age adjusted mean body girths, body mass index and ratios of body girths by sex and ethnicity comparing normoglycaemic and glucose intolerant subjects

\begin{tabular}{|c|c|c|c|c|}
\hline & \multicolumn{2}{|l|}{ Men } & \multicolumn{2}{|l|}{ Women } \\
\hline & $\begin{array}{l}\text { European } \\
(n=246)\end{array}$ & $\begin{array}{l}\text { Afro-Caribbean } \\
(n=177)\end{array}$ & $\begin{array}{l}\text { European } \\
(n=277)\end{array}$ & $\begin{array}{l}\text { Afro-Caribbean } \\
(n=211)\end{array}$ \\
\hline Sagittal diameter $(\mathrm{cm})$ & & & & \\
\hline Normoglycaemic & $\begin{array}{l}210.8^{\mathrm{a}} \\
\mathrm{b}\end{array}$ & 203.8 & $191.0^{c}$ & $\begin{array}{l}210.3 \\
\mathrm{a}\end{array}$ \\
\hline Glucose intolerant & $230.4^{\mathrm{b}}$ & 208.5 & $200.3^{b}$ & 220.9 \\
\hline $\begin{array}{l}\text { Waist girth }(\mathrm{cm}) \\
\text { Normoglycaemic }\end{array}$ & $\begin{array}{l}91.6^{\mathrm{c}} \\
\mathrm{c}\end{array}$ & 87.6 & $78.5^{c}$ & $\begin{array}{l}85.5 \\
\text { a }\end{array}$ \\
\hline Glucose intolerant & $97.1^{\mathrm{c}}$ & 87.2 & $85.8^{\mathrm{b}}$ & 95.6 \\
\hline $\begin{array}{l}\text { Hip girth }(\mathrm{cm}) \\
\text { Normoglycaemic } \\
\text { Glucose intolerant }\end{array}$ & $\begin{array}{l}97.4^{\mathrm{c}} \\
98.6^{\mathrm{a}}\end{array}$ & $\begin{array}{l}93.8 \\
94.1\end{array}$ & $\begin{array}{l}98.1^{\mathrm{c}} \\
100.4\end{array}$ & $\begin{array}{l}101.9 \\
105.3\end{array}$ \\
\hline $\begin{array}{l}\text { Thigh girth }(\mathrm{cm}) \\
\text { Normoglycaemic } \\
\text { Glucose intolerant }\end{array}$ & $\begin{array}{l}56.3 \\
57.2\end{array}$ & $\begin{array}{l}56.7 \\
57.2\end{array}$ & $\begin{array}{l}57.2^{\mathrm{c}} \\
58.4^{\mathrm{b}}\end{array}$ & $\begin{array}{l}62.6 \\
64.4\end{array}$ \\
\hline $\begin{array}{l}\mathrm{BMI}\left(\mathrm{kg} / \mathrm{m}^{2}\right) \\
\text { Normoglycaemic }\end{array}$ & $\begin{array}{l}25.8 \\
\text { b }\end{array}$ & 25.5 & $25.8^{\mathrm{c}}$ & 29.6 \\
\hline Glucose intolerant & 27.7 & 25.7 & $26.4^{\mathrm{b}}$ & 30.7 \\
\hline $\begin{array}{l}\text { WHR } \\
\text { Normoglycaemic }\end{array}$ & $\begin{array}{l}0.94 \\
\mathrm{c}\end{array}$ & 0.93 & $\begin{array}{l}0.80^{c} \\
\mathrm{a}\end{array}$ & $\begin{array}{l}0.84 \\
\mathrm{c}\end{array}$ \\
\hline Glucose intolerant & $0.98^{\mathrm{c}}$ & 0.93 & $0.85^{b}$ & 0.91 \\
\hline $\begin{array}{l}\text { WTR } \\
\text { Normoglycaemic }\end{array}$ & $\begin{array}{l}1.62^{\mathrm{c}} \\
\mathrm{c}\end{array}$ & 1.55 & 1.37 & 1.37 \\
\hline Glucose intolerant & $1.70^{c}$ & 1.53 & 1.47 & 1.48 \\
\hline
\end{tabular}

${ }^{\mathrm{a}} p<0.05 ;{ }^{\mathrm{b}} p<0.01 ;{ }^{\mathrm{c}} p<0.001$ (excludes subjects with known diabetes or hypertension)

Table 4. Age adjusted mean skinfold thicknesses by sex and ethnicity comparing normoglycaemic and glucose intolerant subjects

\begin{tabular}{|c|c|c|c|c|}
\hline & \multicolumn{2}{|l|}{ Men } & \multicolumn{2}{|l|}{ Women } \\
\hline & $\begin{array}{l}\text { European } \\
(n=246)\end{array}$ & $\begin{array}{l}\text { Afro-Caribbean } \\
(n=177)\end{array}$ & $\begin{array}{l}\text { European } \\
(n=277)\end{array}$ & $\begin{array}{l}\text { Afro-Caribbean } \\
(n=211)\end{array}$ \\
\hline $\begin{array}{l}\text { Subscapular skinfold (mm) } \\
\text { Normoglycaemic }\end{array}$ & $\begin{array}{l}17.3 \\
\mathrm{c}\end{array}$ & 18.9 & $20.0^{\mathrm{c}}$ & $\begin{array}{l}28.1 \\
b\end{array}$ \\
\hline Glucose intolerant & 23.2 & 20.8 & $23.0^{\mathrm{c}}$ & 33.6 \\
\hline $\begin{array}{l}\text { Triceps skinfold (mm) } \\
\text { Normoglycaemic }\end{array}$ & $\begin{array}{l}9.9^{b} \\
\mathrm{a}\end{array}$ & 8.5 & $20.6^{c}$ & 24.3 \\
\hline Glucose intolerant & $12.3^{\mathrm{b}}$ & 9.1 & 20.7 & 23.9 \\
\hline $\begin{array}{l}\text { Supra-iliac skinfold (mm) } \\
\text { Normoglycaemic }\end{array}$ & $\begin{array}{l}19.4 \\
b\end{array}$ & $\begin{array}{l}21.1 \\
\text { b }\end{array}$ & $16.1^{c}$ & $\begin{array}{l}22.9 \\
\text { b }\end{array}$ \\
\hline Glucose intolerant & 24.4 & 27.3 & $16.8^{\mathrm{c}}$ & 27.1 \\
\hline $\begin{array}{l}\text { Anterior thigh skinfold }(\mathrm{mm}) \\
\text { Normoglycaemic } \\
\text { Glucose intolerant }\end{array}$ & $\begin{array}{l}12.0^{\mathrm{b}} \\
13.0^{\mathrm{a}}\end{array}$ & $\begin{array}{l}10.3 \\
10.4\end{array}$ & $\begin{array}{l}29.4^{\mathrm{b}} \\
28.4^{2}\end{array}$ & $\begin{array}{l}32.5 \\
32.3\end{array}$ \\
\hline
\end{tabular}

${ }^{\mathrm{a}} p<0.05 ;{ }^{\mathrm{b}} p<0.01 ;{ }^{\mathrm{c}} p<0.001$ (excludes subjects with known diabetes or hypertension)

ceride (Table 5). In all four sex/ethnic groups, triglyceride levels increased with increasing levels of both glucose and insulin, but at each level of glucose and insulin, triglyceride was significantly higher in Europeans than in Afro-Caribbeans (Figs. 1,2).
Obesity in Afro-Caribbeans and Europeans. In normoglycaemic men (Table 3 ), there was no difference between Afro-Caribbeans and Europeans in BMI or WHR, but WTR was significantly higher in Europeans than in Afro-Caribbeans. However, both waist and hip 
Table 5. Correlations between triglyceride, insulin and glucose

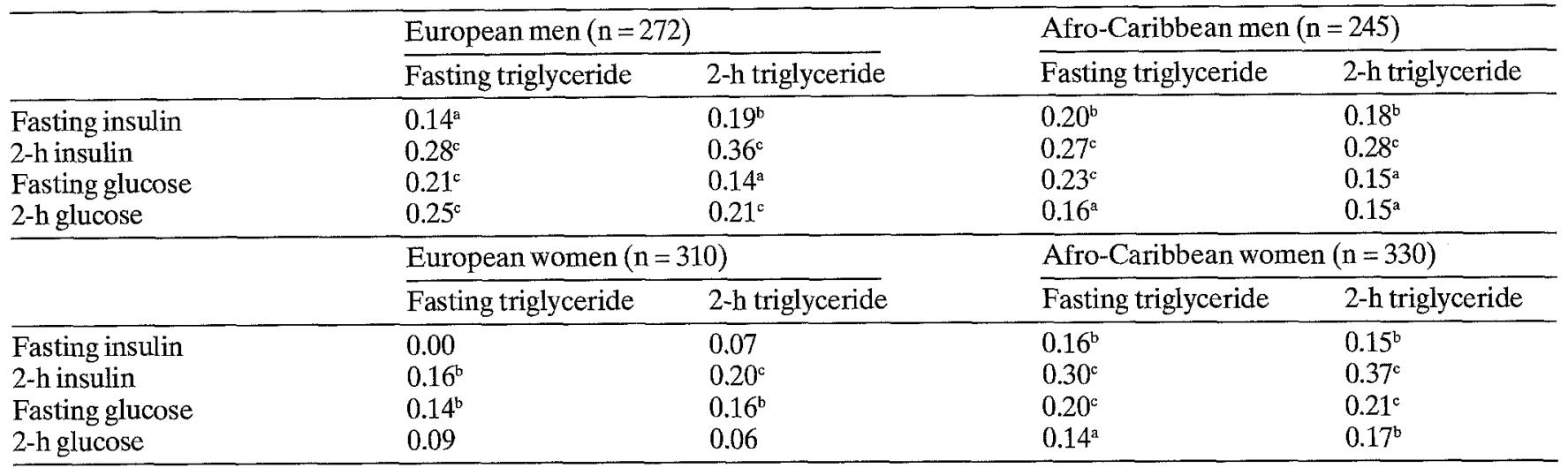

${ }^{\mathrm{a}} p<0.05 ;{ }^{\mathrm{b}} p<0.01 ;{ }^{\mathrm{c}} p<0.001$
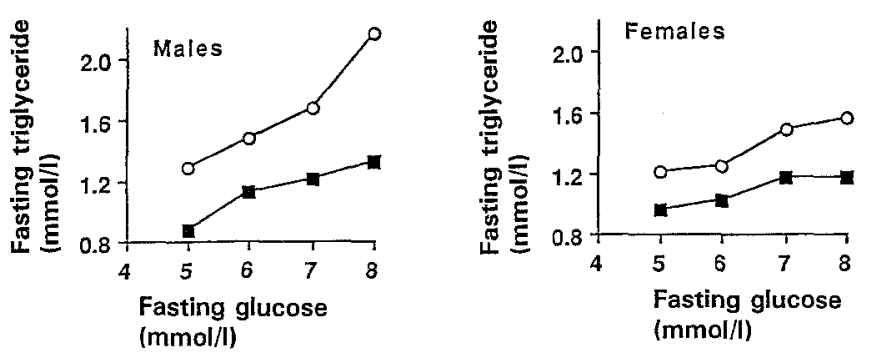

Fig. 1. Fasting triglyceride by category of fasting glucose by sex and ethnicity,-O-O-European; - - Afro-Caribbean
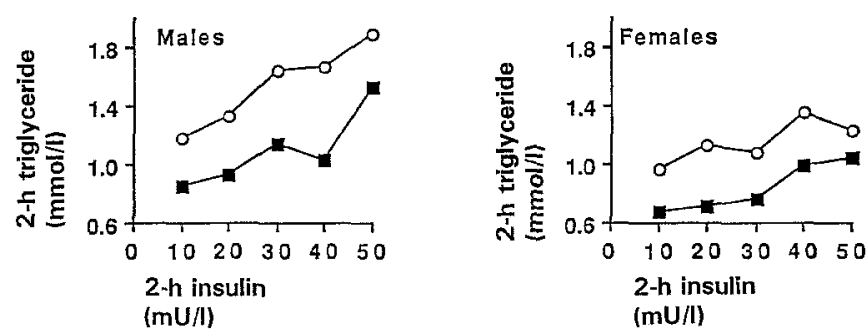

Fig. 2. Triglyceride levels (2-h) (after glucose tolerance test) by category of 2-h hour insulin levels by sex and ethnicity, - European;--Afro-Caribbean

circumferences were significantly greater in European men compared to Afro-Caribbean men, while thigh girth was not significantly different in the two ethnic groups.

In European men, WHR was 0.94 in normoglycaemic subjects, and 0.98 in glucose intolerant subjects $(p<0.001)$, while in Afro-Caribbean men, WHR was 0.93 in both normoglycaemic and glucose intolerant individuals. The ethnic difference in WHR by glucose intolerance was significant when tested as an interaction $(p=0.002)$. Similar findings were observed for WTR, with no significant difference in Afro-Caribbeans with normoglycaemia and glucose intolerance, and an increase in Europeans from 1.62 to 1.70, this interaction was also significant $(p=0.002)$. Sagittal abdominal diameter was greater in European than Afro-Caribbean men, and was only significantly higher in Euro-
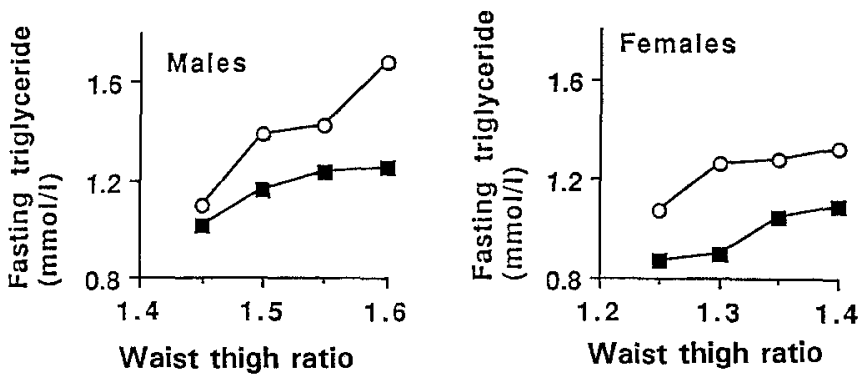

Fig.3. Fasting triglyceride by category of waist thigh ratio by sex and ethnicity, - O-European, - - Afro-Caribbean

pean glucose intolerant compared with normoglycaemic men.

In men, there was no ethnic difference in subscapular and supra-iliac skinfolds, while triceps and anterior thigh skinfolds were greater in European men (Table 4). Subscapular and supra-iliac skinfolds, but not triceps or anterior thigh, were higher in glucose intolerant compared with normoglycaemic European men.

In contrast, Afro-Caribbean women were more obese than their European counterparts by any measure of obesity, and indices of obesity were generally higher in glucose intolerant subjects in both ethnic groups than in normoglycaemic subjects.

Triglyceride levels increased with increasing levels of obesity (using either BMI, WHR or WTR) in both Europeans and Afro-Caribbeans, but at all levels of obesity, mean triglyceride levels were higher in Europeans (Fig. 3).

Further adjustment of fasting triglyceride by fasting glucose, 2 -h insulin and WTR simultaneously in a regression model did not alter the significance of the ethnic difference. In men, the ethnic difference in fasting triglyceride fell from $0.42 \mathrm{mmol} / 1$ to $0.32 \mathrm{mmol} / 1$, while in women, the ethnic difference rose from $0.26 \mathrm{mmol} / 1$ to $0.32 \mathrm{mmol} / \mathrm{l}$. 


\section{Discussion}

Although Afro-Caribbeans in the United Kingdom have a significantly higher prevalence of diabetes than Europeans $[18,19]$, this study shows that the prevalence of CHD in men is lower, in accordance with national mortality data. Further, we show that the ethnic difference in CHD morbidity appears to persist in those with glucose intolerance. Approximately a third of all Afro-Caribbean subjects were glucose intolerant compared with just under one sixth of all European subjects.

As in previous studies, [9, 20-22] Afro-Caribbeans have lower triglyceride levels and Afro-Caribbean men have higher HDL cholesterol than Europeans. Although the numbers of people with glucose intolerance are small, especially for Europeans, we are still able to demonstrate the expected disturbances in lipoproteins and central obesity with glucose intolerance in European men. However, we show that in Afro-Caribbean men, where the numbers of glucose intolerant subjects are larger, glucose intolerance is not associated with changes in either lipoprotein levels or central obesity.

A central pattern of body fat, measured by sagittal abdominal diameter, subscapular skinfold thickness, waist hip ratio or waist thigh ratio, is associated with insulin resistance, raised triglyceride, low HDL cholesterol and increased cardiovascular mortality [19, 23-28]. Our measures of central obesity are not ideal, but studies comparing anthropometric and computed tomography measures of intra-abdominal fat suggest that correlations between these two methods are high [29]. In normoglycaemic men, there is no ethnic difference in WHR, but Europeans have a greater mean WTR than Afro-Caribbeans. European men have both greater waist and hip circumferences than Afro-Caribbean men, so that the mean waist to hip ratio is not different in the two ethnic groups. The ethnic difference in hip circumference may be associated with differences in pelvic anatomical structure, as Afro-Caribbean men have a narrower bony pelvis [30]. WTR may be a more valid measure of central obesity when comparing these populations, but establishing this depends on validation against magnetic resonance imaging or other techniques for imaging body fat.

We have demonstrated that in normoglycaemic individuals, fasting and 2-h insulin levels are higher in Afro-Caribbeans than in Europeans [22]. Whilst conventional insulin assays may cross-react with other products such as proinsulin and split proinsulin [31], the specificity of the assay in normoglycaemic individuals, where less proinsulin is produced, is not clear, and the existence of an ethnic difference in the specificity of this assay is not known. Raised insulin levels are usually associated with raised triglyceride levels [32], and with central obesity [1]. Insulin mediated supresssion of lipolysis may be influenced by body fat distribution; central fat has been shown to be less responsive to the antilipolytic effects of insulin than subcutaneous fat [33]. We suggest that less central obesity in Afro-Caribbean men may result in a greater sensitivity to the antilipolytic effects of insulin compared with European men. This difference in insulin sensitivity may account for the low serum triglyceride levels and the associated high HDL cholesterol levels. Further, this may account for the absence of an association between glucose intolerance and lipoprotein disturbances in Afro-Caribbean men as, unlike their European counterparts, Afro-Caribbean men with glucose intolerance are not significantly more centrally obese than normoglycaemic individuals. These findings support earlier observations in a small number of blacks in the United States with NIDDM, who demonstrated both insulin sensitive and insulin resistant variants of diabetes, the former group had lower triglyceride and higher HDL cholesterol levels [34]. This study did not however measure central obesity.

If central obesity is less prevalent in Afro-Caribbeans, this makes it harder to explain the high rates of diabetes in Afro-Caribbeans. It has been speculated that part of the risk of diabetes in African populations is due to a poorer pancreatic beta-cell reserve, with beta-cell exhaustion resulting in diabetes, unlike Europeans where diabetes is thought to be more strongly associated with insulin resistance [35]. Thus, the insulin secretory response to insulin resistance may decline at a lower level of resistance in Afro-Caribbeans than in Europeans, so that a state of decompensation is reached much more quickly. It may therefore be that it is a deficient insulin response, rather than insulin resistance, that accounts for the high prevalence of diabetes in Afro-Caribbeans.

In contrast to men, Afro-Caribbean women are more obese and more centrally obese than European women. Afro-Caribbean women with glucose intolerance are also significantly more centrally obese than their normoglycaemic counterparts, and this may explain why triglyceride levels are higher and HDL cholesterol levels lower in Afro-Caribbean women with glucose intolerance compared with their European counterparts. This supports other findings which show that women in other ethnic groups lose their sex-specific protection from adverse lipoprotein patterns when people with diabetes are compared [36]. The high prevalence of glucose intolerance in Afro-Caribbean women may explain why the ethnic difference in $\mathrm{CHD}$ mortality is not as striking in women as it is in men.

Although fasting triglyceride levels rise with central obesity in both ethnic groups, at similar levels of waist thigh ratio, fasting triglyceride levels are still higher in Europeans than Afro-Caribbeans. This suggests that differences in central obesity can be only partially responsible for the low rates of CHD in Afro-Caribbeans. Others have also suggested that normoglycaemic centrally obese women of black African descent do not have lipoprotein disturbances to the same extent 
as other populations [37], but they also speculate that indices of central obesity may be less valid when comparing different population groups. A more healthy diet might explain the favourable lipoprotein patterns observed in Afro-Caribbeans. Few studies have directly compared dietary behaviour in the two ethnic groups, and we have very little data of our own on this subject, however, a comparative study from the United Kingdom [38] suggested that dietary composition was similar in Afro-Caribbeans and Europeans. Favourable lipoprotein patterns, whatever the underlying mechanism, may account for the relative protection from CHD enjoyed by Afro-Caribbeans, particularly Afro-Caribbean men. There may therefore be differences by ethnicity in resistance to the effects of insulin on glucose and lipid metabolism; others have noted that the antilipolytic effect of insulin occurs at a lower serum concentration than the stimulation of glucose uptake effects [39]. Thus, Afro-Caribbeans may have a greater sensitivity to the antilipolytic effects of insulin than to its glucose homeostatic effects.

Pima Americans and Mexican Americans are other ethnic groups who are insulin resistant and have high rates of NIDDM and a paradoxical low rate of CHD $[40,41]$. However, unlike blacks, both these groups also have higher triglyceride, and lower HDL cholesterol than comparative European populations [42,43].

In conclusion, we find that Afro-Caribbeans, despite high rates of glucose intolerance, high levels of serum insulin and hypertension, do not display the lipid disturbances which are associated with the insulin resistance syndrome. This may be due to differences in body fat pattern and to the association between central obesity and insulin sensitivity. This may in part explain the favourable lipoprotein pattern in Afro-Caribbeans, and account for the relative protection from CHD.

Acknowledgements. This study was supported by a Medical Research Council programme grant. We are grateful to: Wembley Stadium Medical Centre and Jeffrey Kelson Diabetic Centre, Central Middlesex Hospital for accommodation; family practices at Chalkhill, Craven Park, Brentfield, Law, St Raphaels Way and Talbot Walk; to community organisations for advice and publicity; Smith Kline Beecham for the glucose drink; and all members of the fieldwork team.

\section{References}

1. Reaven GM (1988) Role of insulin resistance in human disease. Diabetes 37; 1595-1607

2. Office of Population Censuses and Surveys (1990) Mortality and geography: a review in the mid-1980s. The RegistrarGeneral's decennial supplement for England and Wales, series DS no. 9, London:HMSO

3. Marmot MG, Adelstein AM, Bulusu L (1984) Immigrant mortality in England and Wales 1970-78. OPCS studies of medical and population subjects no 47, London:HMSO

4. Harris MI (1990) Non-insulin-dependent diabetes mellitus in black and white Americans. Diabetes Metab Rev 6: $71-90$
5. Miller GJ, Beckles GLA, Maude GH et al. (1989) Ethnicity and other characteristics predictive of coronary heart disease in a developing country - principal results of the St James survey, Trinidad. Int J Epidemiol 18: 808-817

6. Keil JE, Sutherland SE, Knapp RG, Tyroler HA (1992) Does equal socioeconomic status in black and white men mean equal risk of mortality. Am J Public Health 82: 1133-1136

7. Tyroler HA, Glueck CJ, Christensen B, Kwiterovich PO Jr (1980) Plasma high-density lipoprotein cholesterol comparisons in black and white populations. The lipid research clinics program prevalence study. Circulation 62:IV99-IV107

8. Slack J, Noble N, Meade TW, North WRS (1977) Lipid and lipoprotein concentrations in 1604 men and women in working populations in north-west London. BMJ 2: 353-356

9. Pacy PJ, Dodson PM, Kubicki AJ, Fletcher RF (1987) Differences in lipid and lipoprotein levels in white, black and Asian non-insulin dependent (type 2) diabetics with hypertension. Diabetes Res 4: 187-193

10. Chaturvedi N, McKeigue PM, Marmot MG (1993) Resting and ambulatory blood pressure differences in Afro-Caribbeans and Europeans. Hypertension 22: 90-96

11. Arnqvist H, Olsson PO, Vonshenck H (1987) Free and total insulin as determined after precipitation with polyethyleneglycol - analytical characteristics and effects of sample handling and storage. Clin Chem 33: 93-96

12. Siedel J, Hagele EO, Ziegenhorn J, Wahlefeld AW (1983) Reagent for the enzymatic determination of serum total cholesterol with improved lipolytic effect. Clin Chem 29: 1075-1080

13. Warnick GR, Benderson J, Albers JJ (1982) Dextran sulfate$\mathrm{Mg} 2$ + -Precipitation procedure for quantitation of high density-lipoprotein cholesterol. Clin Chem 28: 1378-1388

14. Mount JN, Kearney EM, Rosseneu M, Slavin BM (1988) Immunoturbidometric assays for serum apolipoproteins AI and B using Cobas Bio centrifugal analyser. J Clin Pathol 41: 471474

15. WHO Study Group on Diabetes Mellitus (1985) Diabetes mellitus. WHO Tech Rep Ser 727:1-113

16. Rose GA, Blackburn H, Gillum RF, Prineas RJ (1982) Cardiovascular survey methods, Geneva:WHO, Ed. 2

17. Wilcosky T, Harris R, Weissfeld L (1987) The prevalence and correlates of Rose questionnaire angina among women and men in the lipid research clinics program prevalence study population. Am J Epidemiol 125: 400-409

18. Cruickshank JK, Cooper J, Burnett M, MacDuff J, Drubra U (1991) Ethnic differences in fasting plasma C-peptide and insulin in relation to glucose tolerance and blood pressure. Lancet 338: 842-847

19. McKeigue PM, Shah B, Marmot MG (1991) Relation of central obesity and insulin resistance with high diabetes prevalence and cardiovascular risk in South Asians. Lancet 337: 382-386

20. Meade TW, Brozovic M, Chakrabarti R, Haines AP, North WRS Stirling Y (1978) Ethnic group comparisons of variables associated with ischaemic heart disease. Br Heart J 40: 789-795

21. Heiss G, Schonfeld G, Johnson JL, Heyden S, Hames CG, Tyroler HA (1984) Black-white differences in plasma levels of apolipoproteins: the Evans County Heart Study. Am Heart J 108: 807-814

22. Fontbonne A, Papoz L, Eschwege E, Roger M, Saint-Paul M, Simon D (1992) Features of insulin-resistance syndrome in men from French Caribbean islands. Diabetes 41: 1385-1389

23. Larsson B, Svardsudd K, Welin L, Wilhelmsen L, Bjorntorp P, Tibblin G (1984) Abdominal adipose tissue, obesity and risk of cardiovascular disease and death: a 13-year follow-up of participants in the study of men born in 1913. BMJ 288: 1401-1404 
24. Baumgartner RN, Roche AF, Chumlea WC, Siervogel RM, Glueck CJ (1987) Fatness and fat patterns: associations with plasma lipids and blood pressures in adults 18 to 57 years of age. Am J Epidemiol 126: 614-628

25. Krotkiewski M, Bjorntorp P, Sjostrom L, Smith U (1983) Impact of obesity on metabolism in men and women: importance of regional adipose tissue distribution. J Clin Invest 72 : $1150-1162$

26. Foster CJ, Weinsier RL, Birch R et al. (1987) Obesity and serum lipids: an evaluation of the relative contribution of body fat and fat distribution to lipid levels. Int J Obesity 11: 151-161

27. Blair D, Habicht JP, Sims EA (1984) Evidence for an increased risk for hypertension with centrally located body fat and the effect of race and sex on this risk. Am J Epidemiol 119: 526-540

28. Freedman DS, Srinivasan SR, Voors AW, Webber LS, Berenson GS (1985) High density lipoprotein and coronary artery disease risk factors in children with different lipoprotein profiles: Bogalusa Heart Study. J Chronic Dis 38: 327-338

29. Seidell JC, Oosterlee A, Thijssen MAO et al. (1987) Assessment of intra-abdominal and subcutaneous abdominal fat: relation between anthropometry and computed tomography. Am J Clin Nutr 45: 7-13

30. Iscan MY (1983) Assessment of race from the pelvis. Am J Physical Anthropology 62: 205-208

31. Temple R, Clark PMS, Hales CN (1992) Measurement of insulin secretion in type 2 diabetes: problems and pitfalls. Diabetic Med 9: 503-512

32. Reaven GM, Greenfeld MS (1981) Diabetic hypertriglyceridemia: evidence for three clinical syndromes. Diabetes 30 [Suppl 2]: 66-75

33. Bolinder J, Kager L, Ostman J, Arner P (1983) Differences at the receptor and post-receptor levels between human omental and subcutaneous adipose tissue in the action of insulin on lipolysis. Diabetes 32: 117-123
34. Banerji MA, Lebovitz HE (1991) Coronary heart disease risk factor profiles in black patients with non-insulin-dependent diabetes mellitus: paradoxic patterns. Am J Med 91: 5158

35. Joffe BI, Panz VR, Wing JR, Raal FJ, Seftel HC (1992) Pathogenesis of non-insulin-dependent diabetes mellitus in the black population of southern Africa. Lancet 340:460-462

36. Walden CE, Knopp RH, Wahi PW, Beach KW, Strandness Jr $E$ (1984) Sex differences in the effect of diabetes mellitus on lipoprotein triglyeride and cholesterol concentrations. $\mathrm{N}$ Engl J Med 311: 953-959

37. Dowling HJ, Pi-Sunyer FX (1993) Race-dependent health risks of upper body obesity. Diabetes $42: 537-543$

38. Miller GJ, Kotecha S, Wilkinson WH et al. (1988) Dietary and other characteristics relevant for coronary heart disease in men of Indian, West Indian and European descent in London. Atherosclerosis 70: 63-72

39. Schade DS, Eaton RP (1977) Dose response to insulin in man: differential effects on glucose and ketone body regulation. J Clin Endocrinol Metab 44: 1038-1053

40. Nelson RG, Sievers ML, Knowler WC et al. (1990) Low incidence of fatal coronary heart disease in Pima Indians despite high prevalence of non-insulin-dependent diabetes. Circulation 81: 987-995

41. Stern MP, Bradshaw BS, Eifler CW, Fong DS, Hazuda HP (1987) Secular decline in death rates due to ischemic heart disease in Mexican Americans and non-Hispanic whites in Texas, 1970-1980. Circulation 76: 1245-1250

42. Howard BV, Davis MP, Pettitt DJ, Knowler WC, Bennett PH (1983) Plasma and lipoprotein cholesterol and triglyceride concentrations in the Pima Indians: distributions differing from those of Caucasians. Circulation 68: 714-724

43. Stern MP, Haffner SM (1988) Do anthropometric differences between Mexican-Americans and Non-Hispanic whites explain ethnic differences in metabolic variables ? Acta Med Scand [Suppl] 723: 37-44 